\title{
Some Aspects of Digitalization in the Study of Criminal Law Disciplines
}

\author{
I.E. Milova ${ }^{1, *}$, E.A. Milova ${ }^{1}$, D.D. Osipov ${ }^{1}$, and T.A. Kalenteva ${ }^{1}$ \\ *Corresponding author: irina.milova@ro.ru. \\ ${ }^{1}$ Samara State University of Economics, Samara, Russia
}

\begin{abstract}
Digitalization is a part of modern reality. It covers all areas of activity, including the educational process. For the training of lawyers is extremely important transition to the figure in the study of disciplines of criminal law orientation. It is in this area of knowledge that the use of artificial intelligence can give breakthrough results. Electronic formats of training not only develop the logic of thinking of lawyers, giving them a sum of theoretical ideas, but also prepare them for independent practical work, giving them the opportunity to gain professional applied skills. At the same time training simulators, business games, help to identify and develop the ability of students to implement specific law enforcement functions. At the same time, future lawyers develop a non-formal approach to obtaining information, with the transition from its simple perception to a logically oriented search, generalization and application, the ability to identify and identify the problem, to develop an algorithm for its step-bystep solution, to obtain optimally informed conclusions.
\end{abstract}

Keywords: modern education, computer technologies, University education, criminal law Sciences, modern technologies in education.

\section{Introduction}

The modern period of civilization is characterized by the spread of digital technologies. In Russia, public policy is focused on setting priorities in the field of information technology. It is emphasized that the transition to the figure in various fields of activity is one of the strategic objectives that determine the development of the country in the near future [1].

They are quite actively implemented in the educational process [2], including the high school, including the study of the disciplines of criminal law orientation [3]. In fairness, we note that the trend was ambiguously evaluated by the scientific community, because some scientists do not consider this vector measure scientific progress, noting there are a number of serious risks [4].

At the same time, most authors accept this phenomenon as an objective reality, considering it rather promising [5]. Moreover, it is believed that digitalization can really contribute to the breakthrough development of legal science, bringing it to a new conceptual level [6]. With this understanding and orientation training on the formation of students ' competences after graduation, a graduate is ready for independent work on the chosen specialty [7].

\section{Problem Statement}

Russia is a very promising country in the field of digitalization development, as there is a real social demand for the use of information technologies in all spheres of activity, including education. At the same time, legal professionals with such knowledge are in great demand in the investigative bodies, the Prosecutor's office, the judicial system, expert institutions and the bar. The problem is that legal education has long been focused on traditional methods of knowledge transfer, with an emphasis on their simple retransmission. As a result, at the output we received a graduate who was not ready to perform a specific job in the field of law, which required internships, qualification trainings. The transition to innovative forms of education is associated with the active involvement of students in the development of new material, with the development of their skills to find information and the possibility of its practical application.

\section{Research Questions}

We have made an attempt to explore the possibilities of digitalization in the development of students of criminal law disciplines. The role of forensic laboratories, which are a platform for the application of innovative methods of training lawyers, is shown. In addition, some proposals have been made to expand digitalization in this area of information acquisition; the advantages of electronic control methods for checking the residual knowledge slice have been identified. 


\section{Purpose of the Study}

The purpose of this work is to try to summarize the experience accumulated in the Samara state University of Economics in digitizing the educational process of bachelors and masters specializing in this profile. We tried to make specific proposals to expand the use of electronic options for obtaining knowledge in this area, with an emphasis on the formation of students ' competence approach.

\section{Research Methods}

During the research we used such methods as system analysis, structuring, comparison, sociological and experimental approaches, scientific forecasting and modeling.

The basis for the preparation of the study were the publications of domestic and foreign authors, whose research interests are the issues of digitalization of the educational process in the study of criminal law disciplines by lawyers.

At the first stage, we carried out the selection of scientific materials on the chosen research topic, with their subsequent analysis.

At the second stage, the main conclusions of the study were formulated.

\section{Findings}

The Samara State University of Economics has a teaching and methodological office "Forensic Laboratory". Using its technical equipment, students, under the guidance of teachers, gain practical skills, having the opportunity to conduct expert research, with the inclusion of digital techniques. So, during fingerprinting, the automated information retrieval system Papilon is actively used, containing data on fingerprints in the database [8]; during ballistic examinations electronic data banks on firearms and cold steel are used. The laboratory has electronic booklet folders summarizing materials on various expert studies, with conclusions on specific criminal cases. Created electronic content allows you to monitor regional investigative, judicial and expert practice.

The problem is the fullness of forensic suitcases, as the equipment inside them becomes outdated quickly enough. At the same time, digitalization would allow them to be virtually supplemented with modern tools, which, of course, would make the study of forensics more relevant.

In addition, in the educational process, when studying a number of courses in the criminal law cycle, digital photo and video recording tools are used. For example, with their help, educational investigative actions are carried out, such as, inspection of the scene of the incident, verification of testimonies on the spot, presentation for identification. The use of digital equipment increases the accuracy of information consolidation, which, in turn, eliminates subjective moments in its assessment [9].

Information necessary for the study of criminal law disciplines, including tests, training simulators, forensic cases, business game mock-ups, educational films with elements of role-playing games, is stored in electronic format [10], which allows you to quickly find and effectively use it.

Interactive forms are very productive in the educational process, such as a business game - a trial in a criminal case, where students have the opportunity to try themselves in various procedural qualities, both on the part of the prosecution and the defense. Preparing to give speeches, the participants of the simulator game use digital technologies, both for developing a mock criminal case, and in order to study related materials; familiarization with the prevailing investigative and judicial practice in this category of cases.

Invaluable benefit in training is provided by various electronic reference systems and open access to resources on which judicial acts are placed, including in criminal cases. The information available in these databases is used during practical exercises, especially when solving problems-incidents.

Attractive is the creation of various kinds of information banks [11], in different areas of educational work within the framework of the courses being studied. Suppose, it seems advisable to create an electronic bank of methods for investigating economic crimes.

Traditionally, it is important to monitor residual knowledge [12]. Digitization of this process makes it possible to optimize the control procedure for students mastering theoretical material [13] and the formation of their practical application skills. Testing results are placed in the electronic environment of SSUE, with a clear indication of the criteria for their assessment.

It seems useful to create a digital forensic laboratory at the university, where it would be possible to concentrate the efforts of the faculty and students on innovative research, with interactive elements (for example, to create a forensic training ground on the basis of which using digital technologies it would be possible to simulate various forensic situations and work out the methodology and tactics of crime investigation). At the same time, such an innovation would contribute to the revival of publication activity; would introduce a modern orientation in the selection of development topics; would activate the applied component when writing master's theses. 
The corresponding laboratory can be used as a platform for dialogue, including with remote participants on the most pressing problems [14]. The experience of this kind of virtual communication at the university is accumulated. An illustration is the holding of international, All-Russian conferences and round tables on the basis of the SSUE on the fight against extremism, anti-corruption, anti-drug readings.

The equipment of this laboratory is also advisable to use for career guidance work, with the involvement of potential applicants. In this sense, an interesting experience is the holding by the university teachers with the participation of students of master classes in the program "Young forensic scientist". These demonstration games-releases through online broadcasts are shown simultaneously in a number of schools, with the opportunity to participate in the discussion and laboratory research.

In addition, the digital format should be part of preventive work with the public, especially with young people, to prevent crime. The teenage audience, of course, responds better to the video series, with vivid illustrations, accompanied by small in volume, but memorable in content comments. At the same time, online communication is a more familiar format for a youth audience, which helps to establish trustful contacts and get a real response to the issues discussed.

A digital forensic laboratory could become a starting incubator for modern developments in the field of criminal law disciplines, with simultaneous electronic communication with other universities, including foreign ones [15], and practitioners interested in such studies.

Digital technologies are successfully applied at the SSUE as part of the functioning of the Legal Research Center. On the landscape of this structural unit, students, under the guidance of teachers, advise citizens who apply for various legal issues, including remotely, prepare the necessary procedural documents, electronic extracts from legislation, and reference materials. The materials obtained in the legal clinic are effectively used in the educational process as illustrative material, making it lively and practice-oriented.

We see extremely promising digital formats for interaction between lawyers (in the person of teachers, students, practitioners) and IT specialists, in creating projects that are at the junction of criminal law topics and programming. In particular, some stages of the educational process could be robotic, using artificial intelligence as an assistant, both for the teacher and for students. It is, first of all, about working in a forensic laboratory and using this content to control the knowledge gained.

\section{Conclusion}

To summarize what has been said, we note that digitalization is an objective reality [16]. Its task is to optimize social processes, including educational. At the same time, digitization will allow you to optimally quickly receive the information necessary for an in-depth study of criminal law disciplines, free teachers and students from routine technical functions, and expand the speed of their communication with other contractors. Switching to a number in law does not mean giving up creativity, a creative approach, individual serious work, which is characteristic of the legal profession.

\section{References}

1. Decree of the President of the Russian Federation of December 1, 2016 No. 642 "On the Strategy for Scientific and Technological Development of the Russian Federation" (2016). URL: http://www.consultant.ru/document/cons_doc_LAW_207967/. Accessed: 25.09.2019. [in Rus.].

2. The order of the Government of the Russian Federation of July 28, 2017 No. 1632-r "On approval of the program" Digital Economy of the Russian Federation" (2017). URL: http://www.consultant.ru/document/cons doc LAW 221756/. Accessed: 25.09.2019. [in Rus.].

3. M. Goodman, International dimensions of cybercrime. In S. Ghosh, E. Turrini (Eds.), Cybercrimes: A Multidisciplinary Analysis (Heidelberg, Berlin, 2011).

4. V.N. Voronin, Criminal law risks of digital technologies development: Problem statement and research plan. Bulletin of the University O.E. Kutafina, 12, 73-80 (2018). [in Rus.].

5. M.M. Babayev, Risks as a component of the determination of the complex crime. Bulletin of the Nizhny Novgorod Academy of the Ministry of Internal Affairs of Russia, 1(41), 104-110 (2018). [in Rus.].

6. D.S. Latyshev, A brief review of information technology used in legal activity. Innovation Science, 10, 14-17 (2017). [In Rus.]

7. A.H. Dzhatdoev, Information technology in jurisprudence. Young Scientist, 6, 20-24 (2018). [In Rus.]

8. I.P. Rak, Information technology in the activities of law enforcement agencies. Innovation Science, 2-3, 132-135 (2016). [in Rus.].

9. V.A. Meshcheryakov, Digital forensics. The Forensic Library. Science Journal, 4(15), 231-241 (2014). [in Rus.].

10. Ju.V. Gavrilin, A.V. Pobedkin, Gathering evidences in the form of data on electronic media in criminal justice in Russia: Necessarily to improve the procedural form. Proceedings of the Academy of the Ministry of Internal Affairs of Russia, 3(47), 106-112 (2018). [in Rus.] 
11. D. Brown, M. Warschauer, From the university to the elementary classroom: Students' experiences in learning to integrate technology in instruction. Journal of Technology and Teacher Education, 14(3), 599-621 (2006).

12. E. Judson, How teachers integrate technology and their beliefs about learning: Is there a connection? Journal of Technology and Teacher Education, 14(3), 581-597 (2006).

13. C. Pereira, M. Afonso, D. Santos, Educating for entrepreneurship: A new challenge for teacher training institutions. In C.S. Reis, P. Tadeu, T. Paiva (Eds.), Conference on Enabling Teachers for Entrepreneurship Education, Guarda Polytechnic Institute (pp. 50-51). Guarda: Guarda Polytechnic Institute (2013).

14. M. Boulet, B. Boudarbat, The economic performance of immigrants with Canadian education. Regional and Sectoral Economic Studies, 15(2), 23-40 (2015).

15. M. Bouhajeb, H. Mefteh, R.B. Ammar, Higher education and economic growth: The importance of innovation. Atlantic Review of Economics: Revista Atlántica de Economía, 1(01) (2018). URL: https://doaj.org/article/ceafcbafcb2647b08908d1d33c294d95. Accessed: 01.10.2019.

16. P. Uetela, Higher education and the challenges for economic growth in Mozambique: Some evidence. International Journal of Sociology of Education, 4(3), 276-294 (2015). 